\title{
From Knowledge Sharing to Collaborative Decision Making
}

\author{
Pierre-Emmanuel Arduin, Michel Grundstein and Camille Rosenthal-Sabroux \\ LAMSADE, Paris Dauphine University \\ Place du Maréchal de Lattre de Tassigny, 75775 Paris Cedex 16, France \\ pierre-emmanuel.arduin@dauphine.fr,mgrundstein@mgconseil.fr, Camille.Rosenthal- \\ Sabroux@dauphine.fr
}

\begin{abstract}
This paper introduces an approach developed at AXA, a main French insurance company, in order to retain the knowledge acquired by outsourcing teams. This approach is based on the assumption that sharing and disseminating knowledge are two key factors for actually getting knowledge retention. It has been used, tested and improved within AXA France's industrial environment.

By presenting the problem raised by knowledge retention within organizations and the different ways envisaged to improve it, we propose a discussion about their efficiency, and describe our approach in order to retain knowledge in a specific case.

This approach, based on our approach of Knowledge Management, has implied Collaborative Decision Making, which will be highlighted in this paper.

Bridging Knowledge Management and Collaborative Decision Making has been a means to reinforce the ability of the stakeholders to actually retain knowledge and to easily elaborate a consensus, the starting point of an efficient Collaborative Decision Making.
\end{abstract}

Keywords: Knowledge Management, Knowledge Retention, Collaborative Decision Making, Ba, Semi-opened Infrastructure Model (SoPIM).

Biographical notes: Pierre-Emmanuel Arduin is a Ph.D. student in Computer Science at Paris Dauphine University. He studied Psychology, Computer Science and Management, and now focuses on Knowledge Management, which remains his main research topic. Considering that individuals interpret informations and create their own knowledge, he tries to highlight a bridge between Knowledge Management and Collaborative Decision Making. Lecturer at the department of Mathematics and Computer Sciences for Decision and Organizations at Paris Dauphine University, he is also IT and KM consultant within several large companies.

Michel Grundstein is Consulting Engineer and Associated Researcher at LAMSADE (Laboratory focused on analyzing and modeling decision aid systems) Paris Dauphine University. Formerly, he was Corporate Advisor, responsible for Innovative Methods and Applications in the field of information technology, within a French Nuclear Power Plant 
Company (The Framatome Group, now integrated within The AREVA Group). Thus, he had to handle successively: the introduction of Computer-aided Design, the passage from Mainframe computer to Departmental computers and Personal computers, and Artificial Intelligence and Knowledge-based Systems deployment. His main research topic is Knowledge Management seen as management of activities and processes aimed to enhance the utilization and the creation of knowledge within enterprise. For instance, he has initiated the so-called GAMETH ${ }^{\circledR}$ Framework, in order to locate crucial knowledge for business and running processes. His on going research focuses on the elaboration of a Model for Global Knowledge Management within the Enterprise (MGKME). He is the founder, with Camille RosenthalSabroux of the SIGECAD Group, which domain topics are Information System, Knowledge Management and Decision Aid. He has contributed to numerous books as co-author and published several articles (see www.mgconseil.fr website)

Camille Rosenthal-Sabroux is full Professor at Dauphine University, Paris IX. She is a graduate of PHD Pierre et Marie Curie, Paris VI, (1971) and HDR (habilitation à diriger des recherches) in Computer science (1996). From 1976 to 1989, she was assistant professor in Paris XI, in Expert System. Since 1989, she is Professor at Paris Dauphine University, Paris IX and advises some large companies (AG2R, Sallustro Redel Management, Bureau Veristas, PSA Citroën, Arcelor, France Télécom) about Information Systems, Knowledge Mangement, Decision Science. She is the founder, with Michel Grundstein of the SIGECAD Group, which domain topics are Information System, Knowledge Management and Decision Aid. Her main research topics are: Modeling Language (UML), Decision Aid, Knowledge Acquisition, Knowledge Management, Information System. Director of the Master "Extended Company's Information System : Audit and Consulting” She published several books and articles. 


\section{INTRODUCTION}

In Knowledge society, as presented by Sharma et al (2010), knowledge must be considered as a core resource for organizations. So, beyond to be a medium to progress and to innovate, knowledge is one of our most important resources: something necessary to decide.

As emphasized by Liebowitz (2008), organizations that are embracing knowledge retention activities are gaining a competitive advantage. Organizational rearrangements from companies, notably outsourcing, increase a possible lost of knowledge, making knowledge retention sounds as an essential need for them.

When Knowledge is less shared, collaborative decision making seems harder to obtain insofar as a "communication breakdown" characterizes participants' discourse (Kuhn, 1970). At best stakeholders have to found a consensus according to their knowledge. Sharing knowledge ensures its retention and catalyzes the construction of this consensus.

After presenting the industrial context of the knowledge retention problems we have met, we present our visions of collaborative decision making, knowledge in the organization and Knowledge Management. We highlight the requirements and characteristics, but also the strengths and weaknesses of the two main approaches of Knowledge Management: (i) the Technological approach, and (ii) the Managerial and Sociotechnical approach. This finally allows us to see how the elaboration of an appropriated environment has efficiently shared knowledge, supporting several Knowledge Management theories, and has additionally aided people to collaborative decision making.

\section{INDUSTRIAL CONTEXT}

\section{Knowledge retention: a true need}

AXA was created by the fusion between major French insurance groups. Every fusion pulled organizational and technological rearrangements. As a consequence, today the computer equipment of AXA counts more than 32,000 applications. The technology used is the "AXAPAC mainframe” technology. Many updates of a system using this old but efficient technology are a source of errors due to young programmers. Those errors can only be resolved by an expert of the AXAPAC mainframe technology. The problem is that these experts become more and more rare.

The teams working with the AXAPAC mainframe technology are always composed of an expert and a three-year-contract supplier. This organization seems dangerous to the extent that the absence of one expert leads to the loss of an incredible volume of knowledge, notably crucial knowledge: the expertise required to maintain AXAPAC mainframe technology and thus to enable the business activity. Furthermore, the supplier, which is present for three years, cannot acquire fast enough all the knowledge needed to become an AXAPAC mainframe technology expert.

The problems highlighted here are the problem of retaining expert's knowledge and the problem of aggregating experts' and suppliers' decisions. First of all, experts have to share their knowledge in order to enable AXA to retain it. Could this sharing make collaborative decision making easier? How can it be introduced in practice? Reliying on Wilson (2002), Bafoutsou and Mentzas (2002), those are our research questions and they will be answered in this paper. 


\section{Two teams with two different purposes}

Two teams work with the AXAPAC mainframe technology (see Fig. 1):

- The support team: it does a support activity. It is worrying that in spite of coming with changing volume, instant availability is expected from it. It is polarized around a file which simultaneously is a medium to obtain statistics, a pedagogic tool, and a documentary base. This file is called the "incidents' file". When this team has to deal with an incident, the incidents' file is updated. The update is done individually, directly at the end of the process, including information such as the person who investigated it, the date, a description of the demand, a description of the answer, etc. What is entered into the incidents' file is quite clear. What raises more concerns is what comes out from it: this file is difficult to use because it is updated individually. People does not know what it contains, doing collaborative decision making harder to get.

- The quality team: it does a quality activity. It relies on formalized rules which ensure and increase the quality of the AXAPAC mainframe's programs. This activity is worrying less than the support activity: knowledge is considered easier to transfer by the workers.

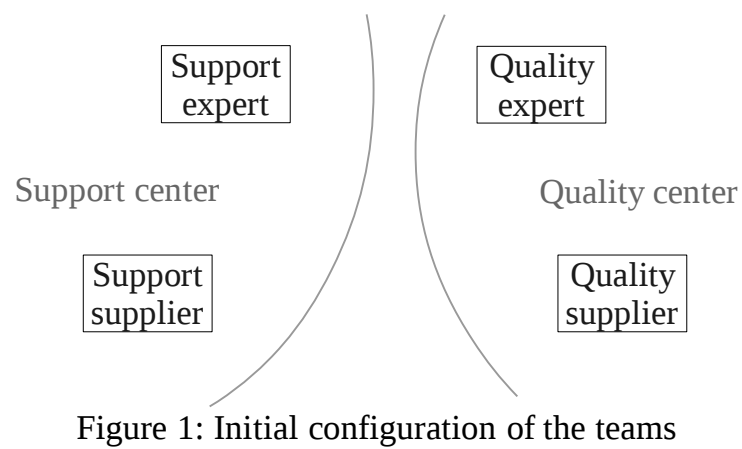

working with the AXAPAC mainframe technology

These teams are both composed of an expert and a three-year-contract supplier. The experts form the newcomer suppliers, and the suppliers assist the experts. Nevertheless, in practice there was so much incidents that the experts and the suppliers were working both on deciding the best way to resolve the incidents. Having no time to discuss, they only updated the incidents' file, without checking the acceptance of what they wrote inside.

Furthermore, this divided organization reinforces the feeling of working alone for the workers. Considering Barratt (2002) in the case of the support center, every worker has its knowledge and its methodology to resolve the incidents, and can thus be viewed as a decisionmaker. Although they are working on the same subject: to resolve incidents on AXAPAC mainframe's programs, they are taking decisions on their own. Knowledge is poorly shared, and collaborative decision making is not envisaged.

\section{BACKGROUND THEORY}

\section{Our vision of collaborative decision making}

As said by Ball et al (1999), one of the maxims of collaborative decision making is that more information is better. Although it has sometimes been extended, the classic decision making process stays the same as its first description by Simon (1960): intelligence, design and choice.

Our vision of collaborative decision making aims not only at increasing the quality of the first parts of the decision making process: intelligence and design, but also at increasing the 
acceptance of the choice. Intelligence and design will be done by more than one individual, and constructed together the decision is more easily accepted. The decided choice will be then a shared choice.

Thereby where decision making could be seen as a constructed model, collaborative decision making, for us, is seen as the use of socio-technical media in order to improve the performance and the acceptability of decision making. The location of knowledge in the realization of collaborative decision making has to be regarded insofar as, according to GzaraYesilbas and Lombard (2004, p. 348), knowledge sharing leads to improve collaborative decision making: a "static view" has to be structured and constitutes the "collaborative knowledge". Knowledge having an important role in individual decision making, we consider that for collaborative decision making, knowledge has to be shared. As said by Olson et al (1993): "What is required is a better understanding of the nature of group work". Knowledge has to be shared, but how do we share knowledge?

\section{Knowledge in the organization}

Tsuchiya (1993), considering tacit knowledge structuring, presents the concepts of "sensegiving" and "sense-reading", which lead us to the following observation: we continuously appropriate information which is not ours. Information is transmitted by speaking, writing, or acting, during a sense-giving process. We perceive some data from that information by listening, reading, or watching, during a sense-reading process. This process activates relevant interpretative frameworks and previous knowledge, depending of the context, our situation and our intention. Eventually, new tacit knowledge is created.

As the authors of this paper, we have got tacit knowledge that we have structured into information during a process of sense-giving. As the readers of this paper, you have interpreted this information perceiving forms and colors, integrated words, data, during a process of sense-reading possibly creating new tacit knowledge (see Fig. 2).

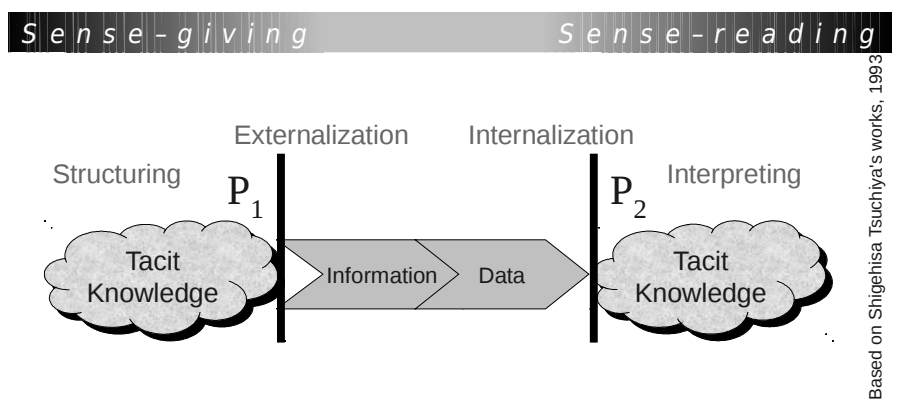

Figure 2: Tacit Knowledge transfert

When a person $\mathrm{P}_{1}$ structures its tacit knowledge and externalizes it, he creates information. A person $\mathrm{P}_{2}$ perceiving some data from this information and internalizing it, possibly creates new tacit knowledge. Thus knowledge is the result of the interpretation of information by someone. This interpretation is done through an interpretative framework that filters data contained in the information and the use of previous tacit knowledge as presented by Tsuchiya (1993).

How can we ensure that the information, regardless who is receiving it, will give the same meaning? How can we avoid the creation of non pertinent knowledge issue from wrongly interpreted information? And more than everything, how can we ensure an efficient knowledge transfer?

The efficiency of knowledge transfer is critical insofar as knowledge cannot exist without people. Retaining knowledge is not reduced to maintaining it. Knowledge continues existing through the actors in presence. If we only store it, for example keeping externalized 
information into a computer, we need someone to interpret this information, someone who has an interpretative framework which allows him to give it the same meaning, and this only, correctly.

If the probability that two people will give the same meaning to the same information is high, it is said that their interpretative frameworks have a strong commensurability. On the contrary, if this probability is low, it is said that their interpretative frameworks have a low commensurability.

Thus it is now clear that the efficiency of a knowledge transfer can be assured if the interpretative frameworks of the actors of this transfer have a strong commensurability. In the same way, in our specific case, collaborative decision making can be considered efficient. The interpretative frameworks of the stakeholders have a strong commensurability, doing a consensus being more evident. Many of our studies aim at setting a mean to measure this commensurability.

Increasing the commensurability of interpretative frameworks allows to consider knowledge as an object. Indeed, it is more and more likely that the same information will have the same meaning for the sender and the receiver. To handle information, for these two people, becomes just the same as to handle knowledge. However how can we handle knowledge?

\section{The two approaches of Knowledge Management}

Most of the time thinking Knowledge Management is thinking in knowledge representation, collaborative or semantic technologies, e-learning, etc. Yet Knowledge Management is not limited to its technological approach, which rests on the codification of explicit knowledge. Knowledge Management includes a managerial and sociotechnical approach which considers knowledge as a resource participating in companies' performance, as presented by Grundstein (2005) and according to Daft and Weick (1984).

The technological approach: here knowledge is considered as an object independent of the person who is handling it. Thus some "knowledge" can be found on collaborative tools or be stored in "knowledge-bases". It is notably the point of view of Grangel, Chalmeta and Campos (2007). This approach is suitable if it is used by people for whom knowledge can be considered as an object: experts, specialized staff, business community, etc. Actually, people whom interpretative frameworks have an extremely strong commensurability. And this is the most important limitation of this approach: knowledge is regarded as an object. An object which can be handled by people who give it a meaning, and the same meaning. Otherwise we will conclude that the knowledge transfer is not efficient.

The managerial and sociotechnical approach: this approach takes into consideration the variety of the situations. It places the constraints of the social system and the specificities of the actors at the heart of its analysis. More supported by Miller (2002) among other, this apporach is centered on the processes but it does not center them on technological solutions conceivable a priori. The managerial and sociotechnical approach is articulated around two purposes :

a) Patrimony purpose aims at knowledge conservation, for its retention and its transfer. It aims also at uncovering tacit knowledge to retain it.

b) Sustainable innovation purpose is complementary to patrimony purpose. It is about encouraging individual knowledge creation, without neglecting its appropriation by the organization. It stimulates knowledge creation from an individual point of view and its retention from the collectivity point of view. This purpose can be regarded as a medium to encourage original decision elaborating and collaborative decision making. 
These two approaches have requirements and characteristics, which make them more or less suitable depending on the expectations and the characteristics from the actors in presence (see Fig. $\underline{3}$ ).

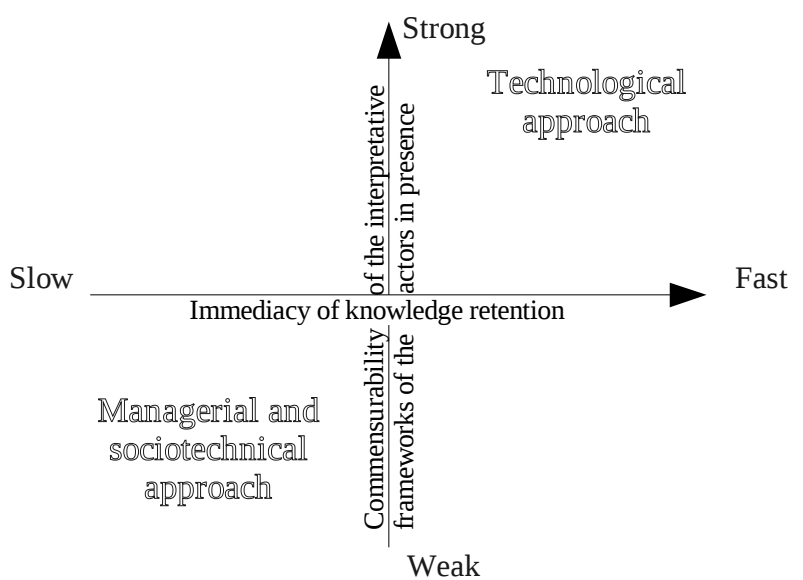

Figure 3: Both approaches, their requirements and characteristics

In the case of people having the same specialty for instance, people of whom their interpretative frameworks have a strong commensurability, the technological approach is completely satisfactory to share knowledge. As long as there is a user to correctly interpret information.

On the contrary, if all the people are not experts, if their interpretative frameworks have a poor commensurability, it is likely that the same information will have different meanings. It is then extremely risky to use the technological approach, which handles knowledge as an object; object which here, does not have the same meaning for everybody. The managerial and sociotechnical approach, as it takes in consideration the specificities of the individuals, ensures enhancing their skills and giving them the means to give the same meaning to the same information.

As much as the commensurability of the interpretative frameworks of the actors will increase, we consider that it will be easier to elaborate collaborative decision making. Sharing the same knowledge and abilities to interpret, they will share more affinities. They will find a consensus easily, starting point of collaborative decision making.

If the technological approach is operational from the beginning, the managerial and sociotechnical approach needs a certain time to ensure an efficient knowledge retention (see Fig. $\underline{3}$ and $\underline{4}$ ). On the base of our observations, we propose a representation from the evolution of the commensurability in both cases (Fig. $\underline{4})$.

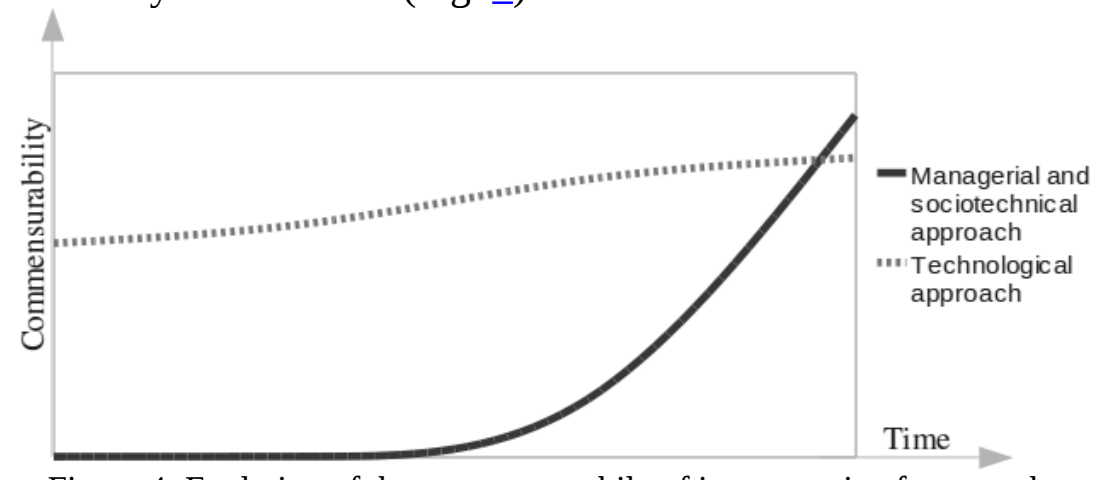

Figure 4: Evolution of the commensurabily of interpretative frameworks

As shown in the Fig. $\underline{3}$, the technological approach, applied in an environment where the actors have strong commensurabilities between their interpretative frameworks is effective. On 
condition that there is always a user of the system able to appropriate correctly and entirely the knowledge.

But then how can we retain knowledge in the case of actors having poor commensurabilities between their interpretative frameworks? How can we prevent the risk of generating incorrect knowledge?

The technology is not enough here. The managerial and sociotechnical approach comes in and reminds the Man that knowledge is not exchanged, it is transferred.

\section{The SECI model and the concept of Ba}

The postulate of the existence of explicit and tacit knowledge (Polanyi, 1958) leads to ask how we can handle tacit knowledge. Relaying on conversions for example from tacit to tacit or tacit to explicit, Nonaka and Takeuchi (1995) proposed a model of knowledge conversion.

1. From tacit to tacit: these authors called it "socialization". A transfer of tacit knowledge is done by watching and practical experience. It is the case for example between a master and his apprentice.

2. From tacit to explicit: it is called the "externalization". An individual shapes his tacit knowledge to share it with a group.

3. From explicit to explicit: it is called the "combination". Several instances of explicit knowledge are combined to constitute new explicit knowledge.

4. From explicit to tacit: it is called the "internalization". By playing and repeating, the individual appropriates the explicit knowledge disseminated in the organization. It becomes, for him, tacit knowledge.

Fig. $\underline{5}$ shows how these conversions follow each other in the style of a spiral: Socialization,

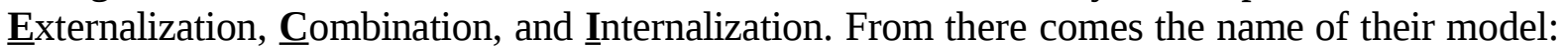
the SECI model.

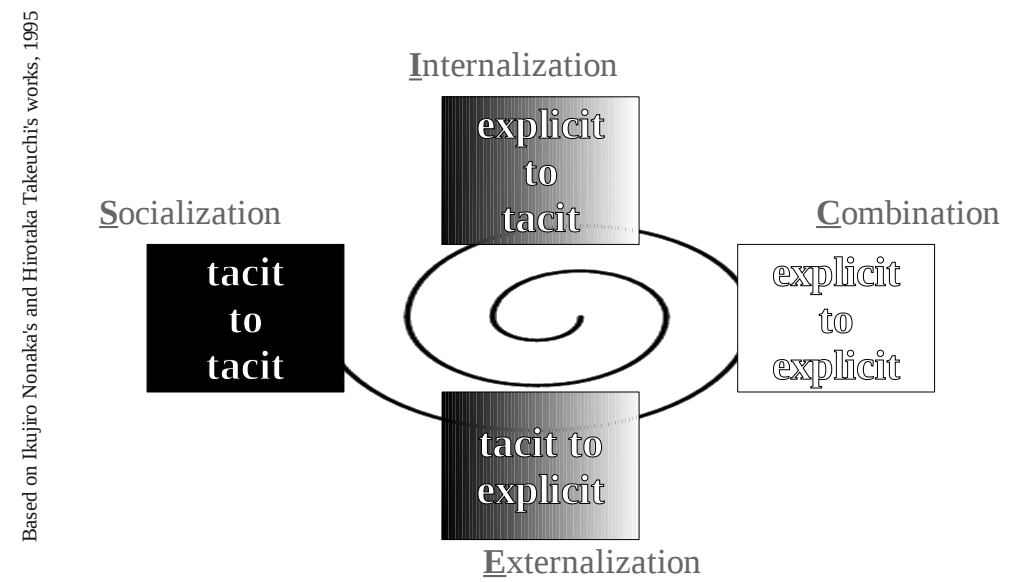

Figure 5: The SECI model

With the concept of "Ba”, Nonaka and Konno (1998) proposed a place to let emerge and / or share tacit knowledge. Concretely, the Ba can be physical (a meeting room for example) or virtual (a collaborative work space for example). It is a place to make progress individual and collective knowledge. Share it to retain it, but also ensure innovation, knowledge creation. That is why the Ba suits perfectly the two purposes of the Knowledge Management in its managerial and sociotechnical approach. It ensures knowledge retention and knowledge appropriation by a group, starting collaborative decision making. 


\section{The semi-opened infrastructure model (SopIM)}

The "semi-opened infrastructure model”, introduced by Grundstein (2005) is rather close to the $\mathrm{Ba}$ to the extent that it sets up conditions leading to the establishment of exchange relations between people. That kind of exchange relations are considered as a base for an efficient knowledge transfer, and consequently, an efficient knowledge retention.

It aims at catalyzing individual learning and collective dissemination of the acquired knowledge.

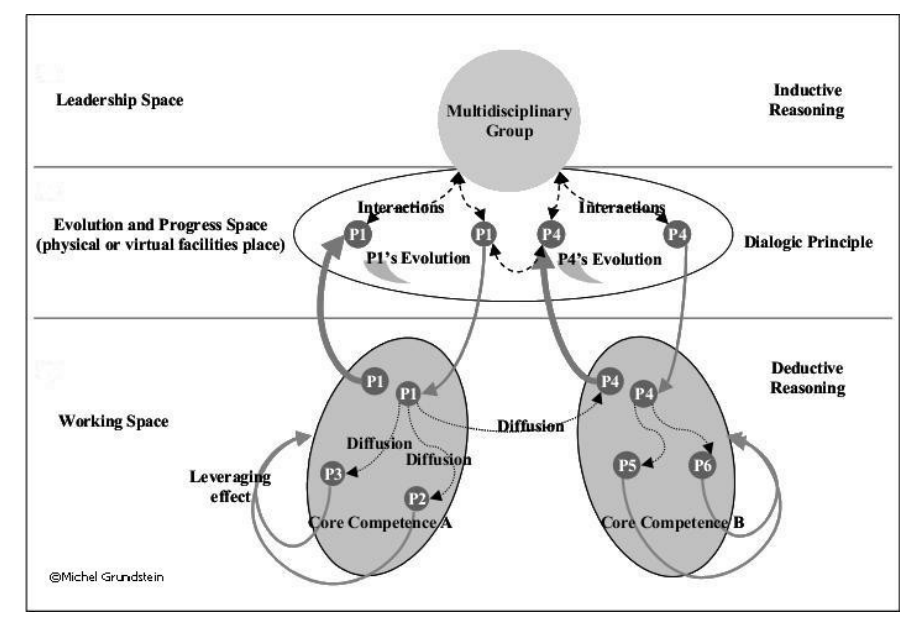

Figure 6: The semi-opened infrastructure model (SopIM)

A "multidisciplinary group" ensures the "evolution and progress space" the capacity of making building up the skills of the actors of the working space. Actors who thereafter disseminate these skills into their working space (see Fig. $\underline{6}$ ).

The SECI model as well as the SopIM, insist on the existence of a space where people can discuss, let emerge some tacit knowledge to share it, to disseminate it, and thus, to retain it, by the building-up skills that these actions have involved. The commensurability of their interpretative frameworks tends to increase, doing, according to our observations, collaborative decision making easier to elaborate.

When the actors are not all experts, when it is impossible to ensure that the same information will take the same meaning for the sender and the receiver, it is now clear that in order to share knowledge, we must create specific spaces where people can interact together. These places will also ensure collaborative decision making: knowledge is discussed, knowledge is shared, and knowledge is appropriated. It is transferred in the sense of Davenport and Prusak that is: "Transfer = Transmission + Absorption (and Use)" (1998, page 101).

\section{THE IMPLEMENTED COLLABORATIVE APPROACH}

In this part we will present the approach developed at AXA France in order to retain the knowledge of the teams working with the AXAPAC mainframe technology. This approach has been used, tested and improved within AXA France's industrial environment. Relying on the elaboration of a collaborative space where the actors can share their knowledge, we observed that this space facilitates collaborative decision making: they now decide together on the best way to solve the incidents. 


\section{A planned rearrangement: the origin of disruptions}

As presented in the first part of this paper (Fig. 1), the teams working with the AXAPAC mainframe technology were divided, what reinforced the feeling of "working alone" for the decision-makers. In order to catalyze knowledge sharing, we suggested merging the knowledge of the teams. We created a "competence center" (Fig. 7). Suppliers will work there on support and quality together. Not only it will ensures knowledge retention, but also it will aid collaborative decision making. We will see now how the disruptions inferred by this rearrangement will imply structural changes instigators of our approach to retain knowledge and to promote collaborative decision making.

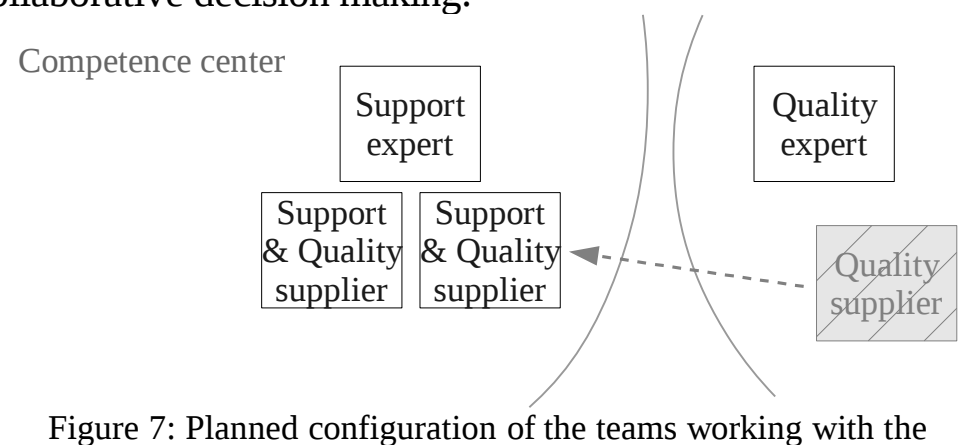

AXAPAC mainframe technology

The idea of this rearrangement is to merge the knowledge of the suppliers so that when a new supplier arrives, the elder is able to assist and form him as in the "socialization" of the SECI model from Nonaka and Takeuchi (1995). The competence center created is the one to work with the incidents' file. This comment is what brings us to the following proposition: "to update together the incidents' file”.

Indeed, the update was done individually, directly at the end of an incident, what implied no dissemination of acquired knowledge and impeded collaborative decision making. Why don't make the actors of the competence center met in order to discuss the incidents, the ways they resolved them, share their knowledge, and then update the file together? There is consequently a dissemination and a sharing of knowledge from where will emerge a consensus on the update of the incidents' file. An update on which everybody will have taken part, resulting of collaborative decision making. An update, which is done by the group and which thus is profitable for the group.

That kind of meetings, which can be weekly, make all the actors of the competence center meet so that they express their tacit knowledge, they share their experiences, their knowledge and they finally disseminate them as in the "externalization" of the SECI model from Nonaka and Takeuchi (1995).

The question of the use of the incidents' file does not raise problems any more: the update resulting of collaborative decision making, every member of the group knows what the file contains, and thus knows what he can search in it. Furthermore, the impregnation of the actors by the contents of the file will be much greater than in the context of an individual update: they talked, exchanged, and all participated in the formalization of their knowledge.

These meetings remind us of the "evolution and progress space" of the semi-opened infrastructure model from Grundstein (2005, see Fig. $\underline{6}$ ). During the time of a meeting, the actors are as in this "evolution and progress space": knowledge is shared by the interactions between them and a "multidisciplinary group". In the case of these meetings which have been called "incidents' meetings", the evolution and progress space, the multidisciplinary group, and the meeting as such are the same. 


\section{The actual rearrangement: the implementation of a Ba}

For practical purposes, when a new supplier arrives we observe that the "socialization" is effectively made between the two suppliers. However, the "socialization" is also effective between the new supplier and every member of the group, what was less predictable. A kind of generalized tacit knowledge sharing was set up at the arrival of the new supplier.

We began planning one incidents' meeting a week. Always in a small meeting room, no more than five persons were present. The duration was generally between one and a half hours and two hours. They were sometimes dangerously too technical at the beginning (only list incidents and solutions, not necessarily understandable by all the stakeholders), but they rapidly became more interactive and make the actors design new axes to optimize knowledge disseminating and sharing. We remind that we consider these two vectors as necessary to retain knowledge in the case of actors having poor commensurabily between their interpretative frameworks, like in such case. The concern is the appropriation of the shared and disseminated knowledge by the actors. From this knowledge sharing they began to think about elaborating collaborative decision making.

If the "socialization" is made when a new supplier arrives and the "externalization" during the incidents' meetings, the "combination" (combination of several instances of explicit knowledge in order to constitute new explicit knowledge) has been observed during these incidents' meetings: tacit knowledge is first externalized and then combined, for instance to elaborate decisions with collaborative decision making. This is a real quality of these incidents' meetings: they not only ensure knowledge retention but also catalyze innovation, knowledge creation, and collaborative decision making. How to optimize knowledge sharing? How to update the incidents' file? These questions and others have been discussed and decided during incidents' meetings.

Practice, repetition and an active participation to the incidents' meetings enable the "internalization": actors appropriate the shared and disseminated knowledge and finally accept the discussed and taken decisions. We are here in a case of application of the SECI model from Nonaka and Takeuchi (1995): knowledge is shared, knowledge is appropriated, knowledge is actually retained, and finally, a place where collaborative decision making can be done has been constructed (see Fig. $\underline{8}$ ), this place is a Ba, as defined by Nonaka and Konno (1998).

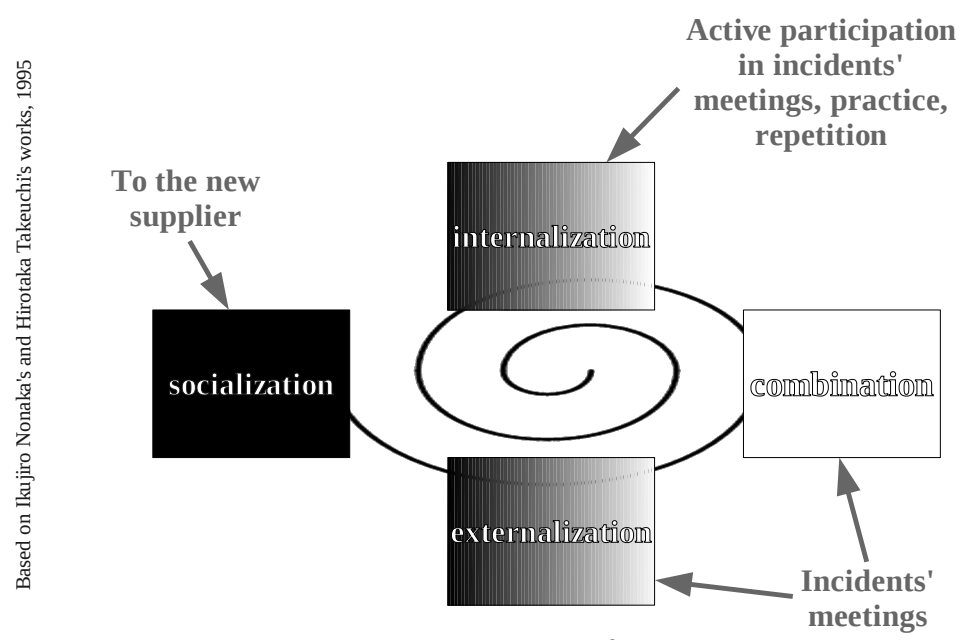

Figure 8: The SECI model in the case of the competence center

A major quality of the incidents' meetings is that they allow their self-amelioration. Thereafter a slight generalization of this self-amelioration has been observed, as if the actors of the competence center tend to spread this passion for knowledge manipulation and collaborative decision making. 
In this way the use of a vocabulary for updating the incidents' file has been suggested. This idea has been immediately and unanimously decided by the group, showing the necessity and the will to normalize the way of updating the incidents' file. Until then the file was updated by the person who dealt with an incident specifying some precise information (processing time, concerned domain, etc.) but also more subjective information (description of the incident, of the decided solution, etc.). Thus, when a similar incident occurred to another person, it was not able to find the first incident in the incidents' file due to the variety of technical vocabulary and to the different expressions used by each author to describe the same incident. Collaborative decision making was difficult to obtain.

A Ba having been developed in the incidents' meetings and the update being now done together, the problem of seeking and finding in the incidents' file will decrease, allowing the actors to discuss and decide together on the best way to solve the incidents discussed during the incidents' meetings.

The idea of the vocabulary restricts the expressiveness of the actors and above all makes them think about what they are about to insert in the incidents' file. The incidents' meetings became thus a place where the actors will discuss the incidents that had been met and the taken decisions to solve them, and now where they will decide about what they are going to insert into the incidents' file: they formalize their knowledge, they synthesize it, and they do it together, ensuring all the actors to appropriate it and to decide it.

So the approach to retain knowledge that we put forward and which facilitates collaborative decision making is articulated around these three dimensions (see Fig. ):

- The incidents' file: indisputable, it collects the information source of the knowledge necessary for the realization of the support activity.

- The organisation: indispensable, it is more about the rearrangement which was at the origin of the incidents' meetings: to conceive a "competence center", and organize meetings there.

- The vocabulary: unnecessary, but requested so much by the team, the creation of a vocabulary ensures the actors that they understand each other and especially that they can easily reuse the information entered in the incidents' file. Nevertheless the complexity of this task has to be taken into consideration: before every entry in the incidents' file, a heavy collaborative decision making must be done to find the most significant and the most important keywords.

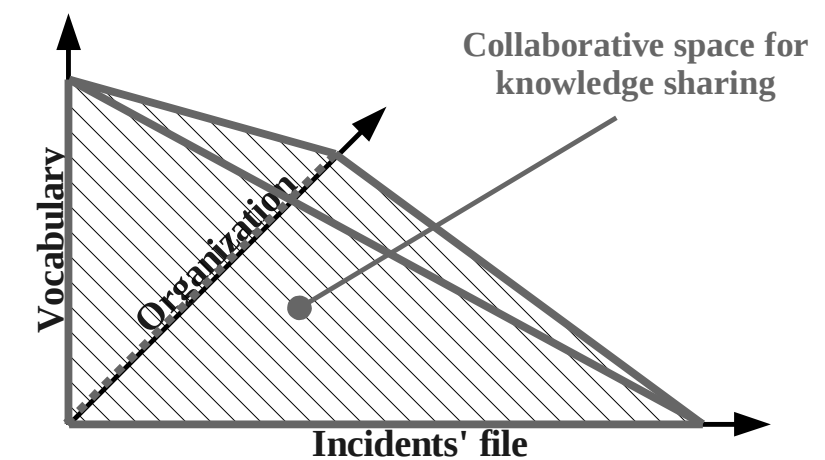

Figure 9: The principle of our approach to retain knowledge

Gradually, the incidents' meetings became more and more generative of discussions concerning the core of the support activity. Discussions in which the various actors of the competence center actively took part, not only the expert, but also the supplier and the newcoming supplier. Working together in the dealing of the incidents and in deciding the formalization of the knowledge necessary to these interventions, each actor appropriated the 
knowledge. This appropriation retain knowledge and makes easier the elaboration of the next decision with collaborative decision making.

By involving people in the implementation of an approach and in the improvement of a process, we make them appropriate the knowledge necessary for the realization of this process.

Within AXA France's industrial environment, our approach has been used, tested and improved. One year after the beginning of this work, the activities of the concerned teams integrate this approach. Knowledge retention became a key step of their activities, and the knowledge retention process continues to give them a place where they can efficiently discuss and initiate collaborative decision making.

\section{RELATED WORKS}

Several works present methods to retain knowledge close to our approach, which is centered on sharing and disseminating knowledge in order to retain it. We think for example of the concept of "thinkLets" introduced by De Vreede (2003) in order to improve collaborative work. It has been observed that improving the quality of collaborative working leaded to improve the sharing of knowledge.

A parallel should be drawn between our vision of collaborative decision making and Raiffa (2002, p. 389) notably, who not only proposes to "look at traditional negotiation advice, organizational behavior, and sociology to illuminate the problem of how to use quantitative methods.", but also to "use quantitative methods and game-theoretic analysis to illuminate negotiation problems". In this paper, we suggested to retain knowledge by sharing it. This sharing increased the commensurability of interpretative frameworks, what, for us, facilitated collaborative decision making. We observed and participated in the collaborative decision making, we observed and participated in the processes.

Considering face-to-face meetings as being the main tool for collaborative decision making, Camilleri and Zaraté (2009) outline an approach to dynamically estimate the efficiency of collective decision making meetings. This can constitute a future for our works: evaluate the commensurability of interpretative frameworks in order to identify people more able to easily work together with collaborative decision making.

Schmidt and Bannon (1992) precise that the term of Computer Supported Cooperative Work (CSCW) also covers the study of the organizational effects of using a collaborative working tool. Our approach can be viewed as an echo to it. Yet it have to be noticed that CSCW is often confused with groupware: computer software designed to cooperative work. Contrarily to Carstensen and Schmidt (1999), our approach does not gives to the workers a technological system in order to share their knowledge and elaborate collaborative decision making. However it gives them the opportunity to decide to design it together, for example deciding to change the structure of the incidents' file.

Jordan (1996) applied a mix of ethnographic methods studying and participating in collaborative decision making processes. She considered Communities of Practice, focusing on "how work is accomplished as a collaborative enterprise" (p. 20). Knowledge is seen as a meaning, what strengthen our approach: knowledge is a meaning, we have to ensure that it is the same for every stakeholder. She insisted on the ethnographic field methods: participant observation, "in-situ question asking" (p. 25) and video review sessions. All of these methods can help to explicit tacit knowledge and share it.

We consider that knowledge has to be shared to ensure its retention. This sharing increases the commensurability of the interpretative frameworks of the stakeholders what, in our specific case, facilitated collaborative decision making. Finding a way to measure the commensurability of interpretative frameworks, would allows us to present quantified data 
supporting this observation. A real strength of our approach is the accent given to the tacit dimension. Several related works presented in this section can complete our approach by giving it a more quantifiable dimension, which is currently one of its weaknesses.

\section{CONCLUSION}

In this paper we began presenting the industrial context of the knowledge retention problems that we have met, and then we introduced background theories, notably our visions of collaborative decision making and of knowledge in the organization. We finally explained our collaborative approach based on these background theories. This approach has been implemented at AXA France, where it has promoted collaborative decision making.

Whereas collaborative decision making was unthinkable because they worked alone, on their own, we have set up an original approach, sometimes viewed as a "strange idea" by the workers: to continue working alone, but discussing once a week how to do the work. These discussions rapidly shared knowledge and this sharing rapidly increased their abilities for collaborative decision making. The implemented $\mathrm{Ba}$ gives them a place where they can efficiently share their knowledge, but also a place where they can create knowledge together, externalizing and combining it. This creation is the basis of collaborative decision making.

Considered as the result of the interpretation of information by someone (Tsuchiya, 1993), knowledge has to be actually shared in order to be retained. By creating an appropriated environment for the actors, giving them a place where they can met, exchange and share, the Knowledge Management, in its managerial and sociotechnical approach considers that an efficient knowledge sharing will be envisaged under these circumstances. This efficient knowledge sharing will be a stiff support to its retention.

A knowledge sharing can be done if we give to the actors a place to do it. This place is a $\mathrm{Ba}$. It is impressive because it simultaneously catalyzes the transfer of knowledge, proposes a support to the updating and the sharing of tacit knowledge, and it has been observed that it promotes collaborative decision making. The actors of the knowledge sharing process have become more and more efficients in terms of performance and acceptability of the decisions elaborated.

Sharing knowledge, thus, increased the commensurability of the stakeholders' interpretative frameworks. This increase not only made knowledge transfer efficient (Davenport and Prusak, 1998, page 101), knowledge is thus retained, but also it facilitates collaborative decision making: a consensus become more evident, as said by Gzara-Yeslbas and Lombard (2004) "collaborative knowledge" is generated, and the risk of "communication breakdown" as said by Kuhn (1970) is reduced.

Many of our current studies aim at setting a mean to measure the commensurability of interpretative frameworks. A perspective to the work presented in this paper is to try to use a measure of the commensurability in order to evaluate the efficiency of knowledge sharing and thus, the predisposition of people to easily work together with collaborative decision making.

Bridging Knowledge Management and Collaborative Decision Making has been here a medium to obtain surprising results, which have highlighted critical aspects of knowledge retention and collaborative decision making: if it is not shared, knowledge is not retained, and if there is no shared knowledge, collaborative decision making is harder to obtain.

\section{REFERENCES}

Bafoutsou, G. and Mentzas, G. (2002) "Review and functional classification of collaborative systems”, International Journal of Information Management, Vol. 22 No. 4, pp. 281-305. 
Ball, M. et al (1999) Collaborative Decision Making in Air Traffic Flow Management, Technical Report RR-99-2, NEXTOR, UC Berkeley.

Barratt, M. (2004) “Understanding the meaning of collaboration in the supply chain”, Supply Chain Management: An International Journal, Vol. 9 No. 1, pp. 30-42.

Bohanec, M. and Kontić, B. (2003) "Collaborative decision making: An environmental case study”, in Mladenić, D. et al (Eds.), Data Mining and decision support: integration and collaboration, Kluwer Academic Publishers, pp. 227-236.

Camilleri, G. and Zaraté, P. (2009) "Towards a dynamic estimation of collective decisionmaking meetings efficiency”, in Kilgour, M. and Wang, Q. (Eds.), Group Decision and Negotiation (GDN) Toronto Canada, pp. 26-29.

Carstensen, P.H. and Schmidt, K. (1999) "Computer Supported Cooperative Work: New Challenges to Systems Design” in Itoh, K. (ed.), Handbook of Human Factors/Ergonomics, Asakura Publishing, Tokyo 2003, pp. 619-636.

Daft,R.L. and Weick, K.E. (1984) "Toward a model of organizations as interpretation systems”, Academy of Management Review, Vol. 9 No. 2, pp 284-295.

Davenport, T.H. and Prusak, L. (1998) Working Knowledge: how organizations manage what they know, Harvard University Press.

Grangel, R., Chalmeta, R. and Campos, C. (2007) “A Modelling Framework for Sharing Knowledge" in KES 2007: Knowledge-Based Intelligent Information and Engineering Systems, Berlin: Springer, pp. 1230-1237.

Grundstein, M., Rosenthal-Sabroux, C. and Pachulski, A. (2003) "Reinforcing decision aid by capitalizing on company's knowledge: Future prospects”, European Journal of Operational Research, Vol. 45, pp. 256-272.

Grundstein, M. (2005) "MGKME: A Model for Global Knowledge Management within the Enterprise” in ICICKM 2005: 2nd International Conference on Intellectual Capital, Knowledge Management and Organizational Learning, American University in Dubai, UAE.

Gzara-Yesilbas, L. and Lombard, M. (2004) "Towards a knowledge repository for collaborative design process: focus on conflict management”, Computers in Industry, Vol. 55 No. 3, pages 335-350.

Jordan, B. (1996) "Ethnographic Workplace Studies and Computer Supported Cooperative Work” in Shapiro, D., Tauber, M. and Traunmüller, R. (Eds.), The Design of ComputerSupported Cooperative Work and Groupware Systems, Amsterdam, The Netherlands: North Holland/Elsevier Science, pp. 17-42.

Kuhn, T.S. (1970) "Reflections on my critics" in Criticism and the growth of knowledge, Lakatos, I. and Musgrave, A. (Eds.), New-York, NY: Cambridge University Press, pp. 231278.

Liebowitz, J. (2008) Knowledge retention: strategies and solutions, CRC Press. 
Miller, F.J. (2002) “I = 0 (Information has no intrinsic meaning)”, Information Research, Vol. 8 No. 1, paper no. 140 [Available at http://InformationR.net/ir/8-1/paper140.html].

Nelson, R.R. and Winter, S.G. (1982) An Evolutionary Theory of Economic Change, Harvard University Press.

Nonaka, I. and Konno, N. (1998) "The concept of « $\mathrm{Ba}$ » : building a foundation for knowledge creation”, California Management Review, Vol. 40 No. 3.

Nonaka, I. and Takeuchi, H. (1995) The Knowledge-Creating Company: How Japanese Companies Create the Dynamics of Innovation, Oxford University Press.

Olson, J.S. et al (1993) "Computer-supported co-operative work: research issues for the 90s'”, Behaviour \& Information Technology, Vol. 12 No. 2, pp. 115-129.

Polanyi, M. (1958) Personal Knowledge: Towards a Post Critical Philosophy, London Routledge.

Raïffa, H. (2002) Negotiation analysis: the science and art of collaborative decision making, Cambridge, Mass. : Belknap Press of Harvard University Press .

Schmidt, K. and Bannon, L. (1992) “Taking CSCW seriously: Supporting articulation work”, Computer Supported Cooperative Work (CSCW), Vol. 1 No. 1, pp. 7-40.

Sharma, R.S. et al (2010) “A Policy Framework for Developing Knowledge Societies”, International Journal of Knowledge Society Research (IJKSR), Lytras, M.D. (ed.), Vol. 1 No. 1, pp. 22-45.

Simon, H. (1960) The new science of management decision, Harper Brothers, New York.

Tsuchiya, S. (1993) "Improving Knowledge Creation Ability through Organizational Learning" in ISMICK 1993: Proceedings of the International Symposium on the Management of Industrial and Corporate Knowledge, UTC, Compiègne, France.

De Vreede, G.J. (2003) “thinkLets: Achieving Repeatable Success with Teams”, Project Management Institute's Midwest Chapter's Annual Conference, Omaha, USA.

Wilson, T. (2002) “The nonsense of 'knowledge management'”, Information Research, Vol. 8 No. 1, paper no. 144 [Available at http://InformationR.net/ir/8-1/paper144.html]. 